\title{
TRATAMENTO DE EFLUENTES ÁCIDOS RICOS EM METAIS COM AUXÍLIO DE SULFETO BIOGÊNICO E CAL
}

\author{
D. GUIMARÃES ${ }^{1}$, K. C. S. LOPES ${ }^{1}$, M. L. M. RODRIGUES ${ }^{1}$, S. M. BERTOLINO² e V. A. LEÃO ${ }^{1}$ \\ ${ }^{1}$ Universidade Federal de Ouro Preto \\ ${ }^{2}$ Universidade Federal de Uberlândia \\ guimaraes.damaris@yahoo.com.br
}

Artigo submetido em novembro/2013 e aceito em dezembro/2013

DOI: http://dx.doi.org/10.15628/holos.2014.1812

\section{RESUMO}

A proposta do presente trabalho foi estudar uma forma de tratamento alternativo para efluentes líquidos ácidos ricos em metais utilizando para isso um efluente sulfetogênico gerado em um reator anaeróbio (UASB utilizado no tratamento de efluentes ricos em sulfato) e cal. Os ensaios foram realizados em batelada utilizando dois efluentes ácidos distintos: (i) um efluente proveniente de ensaios de lixiviação e (ii) um efluente ácido proveniente de um laboratório de pesquisas na área de Bio\&Hidrometalurgia. O efluente dos ensaios de lixiviação apresentou $\mathrm{pH}$ inicial de 1,7 e elevadas concentrações dos metais: Al $(545,5 \mathrm{mg} / \mathrm{L})$, Ca $(668,1$ $\mathrm{mg} / \mathrm{L}), \mathrm{Cu}(37,6 \mathrm{mg} / \mathrm{L}), \mathrm{Fe}(1148,4 \mathrm{mg} / \mathrm{L}), \mathrm{Mg}(1105,9$ $\mathrm{mg} / \mathrm{L})$ e $\mathrm{Ni}(82,3 \mathrm{mg} / \mathrm{L})$, enquanto que o efluente do laboratório era composto por $\mathrm{Cu}(4,8 \mathrm{mg} / \mathrm{L})$, Fe $(342,2$ $\mathrm{mg} / \mathrm{L})$ e $\mathrm{Ni}(3,1 \mathrm{mg} / \mathrm{L})$, sendo o $\mathrm{pH}$ inicial de 0,14. O tratamento consistiu em adicionar o efluente sulfetogênico aos efluentes ácidos, em diferentes proporções, sendo observadas remoções consideráveis dos metais, principalmente, $\mathrm{Fe}$ e $\mathrm{Ni}$, e uma elevação no valor de $\mathrm{pH}$. Em seguida, a fim de se obter melhores resultados de remoção para os metais, os efluentes foram tratados com cal, enquadrando-se aos padrões do CONAMA (resoluções 357/2005 e 430/2011) para o lançamento de efluentes.

PALAVRAS-CHAVE: tratamento de efluentes, sulfeto biogênico, remoção de metais, neutralização.

\section{ACID-HIGH METAL CONTENT-EFFLUENT TREATMENT USING BIOGENIC SULFIDE AND LIME}

\begin{abstract}
The purpose of the present work was to study an alternative way of treatment for acid-high metal contentwastewater using a sulfidogenic effluent generated in anaerobic reactor (UASB - used in the treatment of highsulfate-content effluent) and lime. Assays were conducted in batch-wise using two distinct acid effluents: (i) an effluent from leaching experiments and (ii) an acid effluent from a laboratory research on Bio\&Hydrometallurgy. The leaching effluent showed an initial $\mathrm{pH}$ of 1.7 and high concentrations of metals: Al (545.5 mg/L), Ca (668.1 mg/L), Cu (37.6 mg/L), Fe (1148.4 $\mathrm{mg} / \mathrm{L}), \mathrm{Mg}(1105.9 \mathrm{mg} / \mathrm{L})$ and $\mathrm{Ni}(82.3 \mathrm{mg} / \mathrm{L})$ and the
\end{abstract}

acidic effluent was characterized by the presence of metals: $\mathrm{Cu}(4.8 \mathrm{mg} / \mathrm{L}), \mathrm{Fe}(342.2 \mathrm{mg} / \mathrm{L})$ and $\mathrm{Ni}(3.1 \mathrm{mg} / \mathrm{L})$, and an initial $\mathrm{pH}$ of 0.14 . The treatment consisted in adding, in erlenmeyers, the sulfidogenic effluent to the acid effluents in different proportions, from which were observed a great removal of the metals mentioned, mainly iron and nickel, and a rise in the $\mathrm{pH}$. Then, aiming to reach better results on the other metals removal, the effluents were treated with lime and have framed to the standards of the Brazilian legislation for effluent discharge (CONAMA resolutions 357/2005 and 430/2011). 


\section{INTRODUÇÃO}

A lixiviação ácida é uma tecnologia empregada na metalurgia extrativa, cujo método consiste na separação do metal de interesse presente no minério por processos envolvendo soluções aquosas ${ }^{1}$. Entretanto, com esse processo observa-se a geração de quantidades apreciáveis de efluentes líquidos ricos em metais dissolvidos, os quais normalmente não recebem o devido tratamento, sendo descartados de forma inadequada. Dentre os efluentes gerados pelo setor mínero-metalúrgico, merece destaque a drenagem ácida de mina (DAM), a qual também se caracteriza pelos altos teores de metais dissolvidos e baixo $\mathrm{pH}^{2}$.

Tais efluentes merecem atenção especial, pois estão associados a inúmeros impactos ambientais como o aumento da acidez de solos e águas e o aumento do teor de sais dissolvidos nos corpos hídricos ${ }^{2,3,4}$. Além disso, são responsáveis por vários problemas de saúde em seres humanos e animais, caso sejam descartados sem o devido tratamento em corpos hídricos destinados ao abastecimento humano ${ }^{4}$.

Visando à adequação para o descarte, conforme a Resolução 357/2005 e 430/2011 do Conselho Nacional do Meio Ambiente ${ }^{5,6}$, o tratamento de efluentes é uma necessidade das fontes geradoras, inclusive do setor mínero-metalúrgico. Nesse sentido, o tratamento convencional de efluentes ácidos e ricos em metais normalmente é feito pela adição de cal (CaO), elevando o pH e precipitando os metais na forma de hidróxidos. Apesar de ser bastante usual, esse processo de tratamento apresenta como suas principais desvantagens a grande quantidade de reagente necessária para a neutralização da acidez e precipitação dos metais e, consequentemente, a geração de grandes quantidades de lodo ${ }^{3}$. Dessa forma, é de fundamental importância o desenvolvimento de uma metodologia que seja eficiente (i) na neutralização e remoção dos metais presentes no efluente e que (ii) minimize o excesso de lodo gerado durante o tratamento do efluente.

Nessa perspectiva, o uso da precipitação de sulfetos metálicos para o tratamento de efluentes contendo metais vem ganhando destaque nas últimas décadas. Tal fato se deve às vantagens apresentadas por esse processo em relação aos tradicionais métodos que promovem a precipitação de hidróxidos ${ }^{7}$. Em decorrência dessa tendência, surgiu o emprego do sulfeto de hidrogênio $\left(\mathrm{H}_{2} \mathrm{~S}\right)$ biologicamente produzido em reatores anaeróbios por bactérias redutoras de sulfato (BRS), o qual tem como principais características químicas as elevadas concentrações de alcalinidade $\left(\mathrm{HCO}_{3}{ }^{-}\right.$, entre 1500 e $\left.3000 \mathrm{mg} / \mathrm{L}\right)$ e do íon sulfeto ( $\mathrm{HS}^{-}$e $\mathrm{S}^{-}$, entre 100 e $\left.200 \mathrm{mg} / \mathrm{L}\right)^{8}$.

O processo de produção biológica do sulfeto e alcalinidade pelas BRS pode ser descrito pela reação 1 , na qual $\mathrm{CH}_{2} \mathrm{O}$ representa a fonte de carbono e elétrons.

$$
2 \mathrm{CH}_{2} \mathrm{O}_{(\mathrm{aq})}+\mathrm{SO}_{4}{ }^{2-}{ }_{(\mathrm{aq})} \rightarrow \mathrm{H}_{2} \mathrm{~S}_{(\mathrm{g})}+2 \mathrm{HCO}_{3}^{-}{ }_{(\mathrm{aq})}^{-}
$$

O sulfeto de hidrogênio biogênico produzido na reação 1 precipita os metais dissolvidos como sulfetos de baixa solubilidade, de acordo com a reação 2, na qual $\mathrm{M}^{2+}$ denota o metal, como $\mathrm{Zn}^{2+}, \mathrm{Cu}^{2+}, \mathrm{Ni}^{2+}, \mathrm{Co}^{2+}, \mathrm{Fe}^{2+}, \mathrm{Hg}^{2+}, \mathrm{Cd}^{2+}$ ou $\mathrm{Ag}^{+}$.

$$
\mathrm{H}_{2} \mathrm{~S}_{(\mathrm{g})}+\mathrm{M}^{2+}{ }_{(\mathrm{aq})} \rightarrow \mathrm{MS}_{(\mathrm{s})}+2 \mathrm{H}^{+}{ }_{(\mathrm{aq})}
$$


A introdução de alcalinidade (bicarbonato) proveniente do efluente sulfetogênico neutraliza a acidez da água, como descrito na reação 3 .

$$
\mathrm{HCO}_{3}^{-}{ }^{-}{ }^{\mathrm{aq}}{ }^{-}+\mathrm{H}^{+}{ }_{(\mathrm{aq})} \rightarrow \mathrm{CO}_{2(\mathrm{~g})}+\mathrm{H}_{2} \mathrm{O}_{(\mathrm{l})}
$$

Dentro desse contexto, a proposta do presente trabalho foi de estudar um tratamento alternativo para efluentes líquidos ácidos com alto teor de metais utilizando um efluente sulfetogênico. A adição de alcalinidade no efluente ácido resultaria no aumento do $\mathrm{pH}$, enquanto que o íon sulfeto seria responsável pela precipitação dos metais na forma de sulfetos metálicos. Dessa forma, o tratamento visa a uma total ou parcial neutralização da acidez e precipitação dos metais minimizando o gasto com reagentes alcalinos e a produção de lodo, sendo a cal utilizada apenas no final do tratamento do efluente para ajustar o pH e a concentração dos metais, quando necessário.

\section{MATERIAIS E MÉTODOS}

Os ensaios foram realizados em sistema de batelada, em erlenmeyers de $250 \mathrm{~mL}$, utilizando-se dois efluentes ácidos ricos em metais distintos: (i) um efluente proveniente de ensaios de lixiviação, identificado como E-Lix e (ii) um efluente ácido proveniente das atividades de pesquisa do laboratório de Bio\&Hidrometalurgia da UFOP, denominado efluente ácido E-Lab. O efluente sulfetogênico (E-Sul) foi adicionado ao E-Lix em diferentes proporções volumétricas (ELix: E-Sul) que variaram de 1:3 a 1:10 e ao E-Lab nas proporções volumétricas de 1:10 a 1:100 (ELab:E-Sul). Para isso, registrou-se o pH inicial de cada efluente separadamente, efetuou-se a mistura de ambos, esperou-se a estabilização do sistema e verificou-se o pH final. Em seguida, o precipitado formado foi separado por filtração e a solução filtrada teve seus metais quantificados pela técnica de emissão ótica por plasma indutivamente acoplado (ICP-OES), utilizando um aparelho da marca Varian, modelo 725-ES.

A partir desses ensaios, observou-se a remoção de metais em todas as condições adotadas de acordo com análise feito pelo ICP-OES e a elevação do pH do meio. Porém, como na proporção de 1:1 os resultados obtidos ficaram mais distantes dos estabelecidos pela legislação brasileira vigente ${ }^{4,5}$, prosseguiu-se com os ensaios fazendo os testes com cal para verificar a viabilidade de utilização desse composto na adequação desses efluentes, previamente tratados com efluente sulfetogênico. Dessa forma, à solução filtrada $(100 \mathrm{~mL})$ dos ensaios realizados na proporção de 1:1 (E-Lix:E-Sul) e 1:10 (E-Lab:E-Sul), foram adicionadas massas conhecidas de óxido de cálcio até que fossem atingidos valores de $\mathrm{pH}$ próximos aos pré-estabelecidos (entre 7 e 9). Em seguida, o precipitado formado foi separado por filtração e a solução filtrada teve seus metais novamente quantificados pela técnica de ICP-OES.

Foram feitos ensaios controle com os dois efluentes separadamente sem a adição do efluente sulfetogênico para fins de comparação entre os resultados. Para isso, realizaram-se os mesmos procedimentos adotados anteriormente. $\mathrm{O} \mathrm{pH}$ inicial de cada efluente foi previamente medido e posteriormente adicionado massas conhecidas de cal para se alcançar valores de $\mathrm{pH}$ próximos aos pré-estabelecidos (entre 7 e 9).

A Figura 1 apresenta esquematicamente a sequência de etapas envolvidas na metodologia adotada no presente trabalho. 


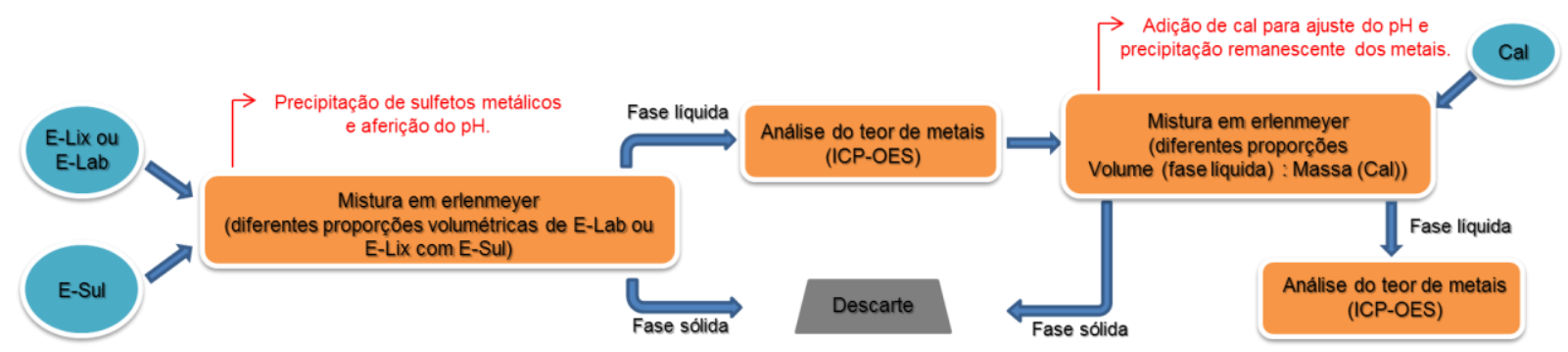

Figura 1 - Fluxograma apresentado todas as etapas realizadas no tratamento dos efluentes E-Lix e E-Lab utilizando E-Sul e Cal.

\section{RESULTADOS E DISCUSSÃO}

A caracterização química do efluente ácido do laboratório (E-Lab) e do efluente dos ensaios de lixiviação (E-Lix) é apresentada na Tabela1, juntamente com os limites estabelecidos pelo CONAMA $(357 / 2005 \text { e 430/2011) })^{4,5}$ para lançamento de efluentes.

Tabela 1- Caracterização química dos efluentes ácidos e concentração limite dos parâmetros estabelecidos pelo CONAMA $^{4,5}$ (teores em $\mathrm{mg} / \mathrm{L}$ ).

\begin{tabular}{ccccccccc}
\hline Efluente & pH inicial & $\mathbf{C u}$ & $\mathbf{N i}$ & $\mathrm{Zn}$ & $\mathrm{Fe}$ & $\mathrm{Al}$ & $\mathrm{Ca}$ & $\mathrm{Mg}$ \\
\hline E-Lab & 0,14 & 4,8 & 3,1 & - & 342.2 & - & - & - \\
E-Lix & 1,7 & 37,6 & 82,3 & 18,0 & 1148,4 & 545,5 & 668,1 & 1005,9 \\
Limite CONAMA ${ }^{4,5}$ & $6-9$ & 1,0 & 2,0 & 5,0 & 15,0 & - & - & - \\
\hline
\end{tabular}

De acordo com Tabela 1, observa-se que ambos os efluentes são extremamente ácidos e que apresentam em sua composição metais em concentrações muito acima dos limites estabelecidos pelas resoluções 357/2005 e 430/2011 do CONAMA ${ }^{5,6}$. Principalmente, no caso do E-Lix, no qual os metais $\mathrm{Cu}$, Ni e Fe encontram-se, respectivamente, cerca de 35, 80 e 75 vezes acima dos limites impostos pela legislação. Com base nessas características, destaca-se que ambos os efluentes apresentam, portanto, o perfil adequado para serem tratados pela técnica proposta no presente trabalho, ou seja, alta acidez e altas concentrações de metais.

\subsection{Tratamento efluente ácido proveniente do laboratório de pesquisa}

Os resultados do tratamento do efluente ácido de um laboratório de pesquisa (E-Lab) em função da razão E-Lab: E-Sul (v/v) podem ser observados na Figura 2. O tratamento do E-Lab pela neutralização/precipitação com E-Sul proporcionou eficientes remoções atingindo o limite estabelecido pelas resoluções $357 / 2005$ e $430 \mathrm{mg} / \mathrm{L}$ do CONAMA para lançamento de efluentes ${ }^{4,5}$ para os metais ferro (15 mg/L) e níquel ( $2 \mathrm{mg} / \mathrm{L})$, a partir da proporção de 1:50. Uma remoção de $96 \%$ de ferro foi alcançada (Figura 2a), correspondendo a uma concentração residual de $14 \mathrm{mg} / \mathrm{L}$, enquanto que, para o níquel (Figura $2 \mathrm{~b}$ ), a eficiência de remoção foi de praticamente $100 \%$. A estabilização na concentração residual do cobre, em $3 \mathrm{mg} / \mathrm{L}$, foi observada para proporções acima de 1:10 (Figura 2c), contudo não foi atingido o valor estabelecido como padrão de lançamento para 
esse elemento, o qual é de $1 \mathrm{mg} / \mathrm{L}$. Portanto, nessa proporção foi realizado um tratamento posterior com cal, para remoção dos metais residuais e neutralização do pH.

O tratamento desses efluentes são necessários devido aos danos à saúde que esses metais podem provocar. Compostos contendo níquel $\left(\mathrm{Ni}^{2+}\right.$ e $\left.\mathrm{Ni}^{3+}\right)$ são carcinogênicos e compostos contendo níquel metálico apresentam indícios de carcinogenicidade. A ingestão excessiva de níquel está associada à ocorrência de problemas relacionados ao comprometimento da integridade e desempenho do sistema reprodutivo ${ }^{9}$. Em se tratando do ferro, a organização mundial de saúde não estabelece um valor de referência para a água de consumo humano, mas afirma que a mesma, contendo até $2 \mathrm{mg} / \mathrm{L}$, não apresenta riscos à saúde humana ${ }^{3}$.
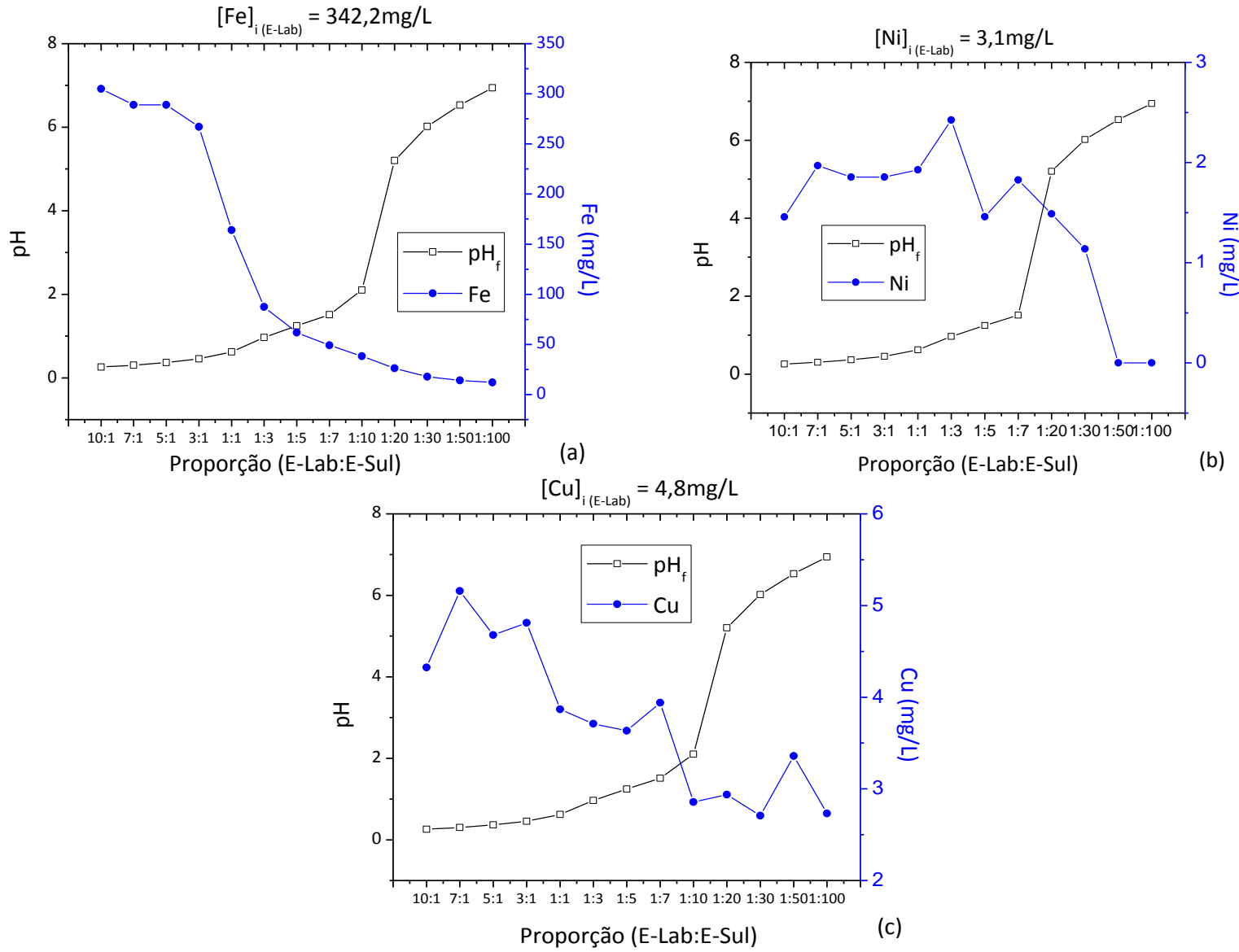

Figura 2 - Evolução da concentração dos metais e do pH em função da razão E-Lab:E-Sul.

\subsection{Tratamento efluente ácido gerado em ensaios de lixiviação}

Os dados obtidos com o tratamento do efluente ácido proveniente ensaios de lixiviação (ELix) podem ser observados na Figura 3. A partir desses, observa-se que a concentração residual do cobre foi de 3,5 mg/L para proporções acima de 1:3 (E-Lix:E-Sul) (Figura 3g). É interessante destacar que, no tratamento de ambos os efluentes, os teores finais de cobre foram próximos entre si, inclusive no caso de E-Lix, cuja concentração inicial desse metal era muito mais alta que a de E-Lab (37,6 mg/L contra $4,8 \mathrm{mg} / \mathrm{L}$, respectivamente). Essa concentração final observada se deve à solubilidade do sulfeto de cobre nas condições experimentais em que os ensaios foram conduzidos. Logo, mesmo havendo sulfeto biogênico e $\mathrm{Cu}$ II no sistema, nessas condições, a concentração final mais baixa possível de se observar para esse íon metálico é próxima aos valores permitidos pela sua solubilidade do sulfeto de cobre. 
Outro fato interessante é que, apesar de E-Lab apresentar uma concentração inicial de cobre bem menor que E-Lix, para se chegar à concentração final de $3 \mathrm{mg} / \mathrm{L}$, esse último efluente foi tratado com uma mistura com E-Sul muito mais concentrada em sulfeto biogênico que E-Lix, ou seja, essa concentração final de cobre foi obtida em ambos os casos nas proporções de 1:10 (ELab:E-Sul) e 1:3 (E-Lix:E-Sul). Nesse caso, a quantidade a mais de efluente sulfetogênico utilizada para elevar o $\mathrm{pH}$ da mistura para 7 foi necessária pelo fato de o E-Lab apresentar o pH inicial mais baixo que do E-Lix. Logo, uma maior quantidade de alcalinidade era requerida para a neutralização desse efluente. Como a fonte de alcalinidade nesse caso era o E-Sul, uma maior quantidade do mesmo foi necessária. Porém, o emprego dessa quantia extra de E-Sul não foi capaz de aumentar a remoção de cobre no sistema, pois, conforme mencionado anteriormente, a saturação do sulfeto de cobre nas condições experimentais adotadas já havia sido atingida.

Para os metais níquel e ferro (Figura 3, respectivamente, $f$ e $d$ ), os resultados foram satisfatórios para proporções E-Lix:E-Sul acima de 1:5 (Ni) e 1:7 (Fe), com eficiências de remoção superiores a $97 \%$ (residual de 1,5 mgNi/L e $8 \mathrm{mgFe} / \mathrm{L}$ ). Para os metais cálcio e magnésio (Figura 3, respectivamente, a e b), o CONAMA ${ }^{4,5}$ não apresenta uma regulamentação específica, mas 0 tratamento de efluentes contendo esses elementos se torna necessário, pois os mesmos podem causar o aumento na dureza da água. Pelo tratamento, foi atingido remoções de $89 \%$ de cálcio e de $91 \%$ para o magnésio. No tratamento proposto, sugere-se que a alcalinidade foi responsável pela precipitação do alumínio na forma de hidróxidos. Pela Figura 3 (c), observa-se que para valores de $\mathrm{pH}$ acima de 3,5 uma significativa remoção do metal, apresentando uma concentração residual de $41 \mathrm{mg} / \mathrm{L}$.

A remoção desses elementos de efluentes líquidos é importante, pois, dentre os principais impactos ambientais relacionados ao lançamento de efluentes ricos em metais, está a contaminação de corpos hídricos, os quais podem atingir mananciais de abastecimento sendo responsáveis por inúmeros efeitos deletérios à saúde humana. Tais efeitos se manifestam de forma aguda ou crônica, conforme o teor administrado de cada metal presente na água e a forma de contato com tal elemento ${ }^{3}$. Dentro desse contexto, conforme pode ser visto (Tabela 1; Figuras $2 \mathrm{e}$ $3)$, após aplicar a metodologia de tratamento proposta no presente trabalho, foi observado que o teor dos metais contido inicialmente nos efluentes foi reduzido para valores dentro dos limites estabelecidos pelo CONAMA ${ }^{4,5}$.

Para o alumínio, há indícios de que o mesmo possa estar relacionado ao surgimento de doenças como o mal de Alzheimer (consumo de água contendo mais que $100 \mu \mathrm{g} / \mathrm{L}$ ) ${ }^{3}$. Os órgãos mais afetados pela contaminação por alumínio são os pulmões, os ossos e o sistema nervoso. Os sistemas reprodutores, feminino e masculino, também podem ser afetados. Para o zinco, o CONAMA $^{4,5}$ estabelece o limite de $5 \mathrm{mg} / \mathrm{L}$ para o lançamento em corpos receptores ${ }^{8}$. Porém, a $\mathrm{WHO}^{3}$ afirma que o consumo de água contendo até $3 \mathrm{mg} / \mathrm{L}$ não apresenta riscos à saúde humana. Conforme observado na Figura 3 (e), a eficiência de remoção do Zinco foi de praticamente 100\% (proporção E-Lix:E-Sul de 1:3). Acima dessa proporção, ocorreu uma redissolução do metal, o que pode ter ocorrido devido à precipitação de outros sulfetos metálicos. 

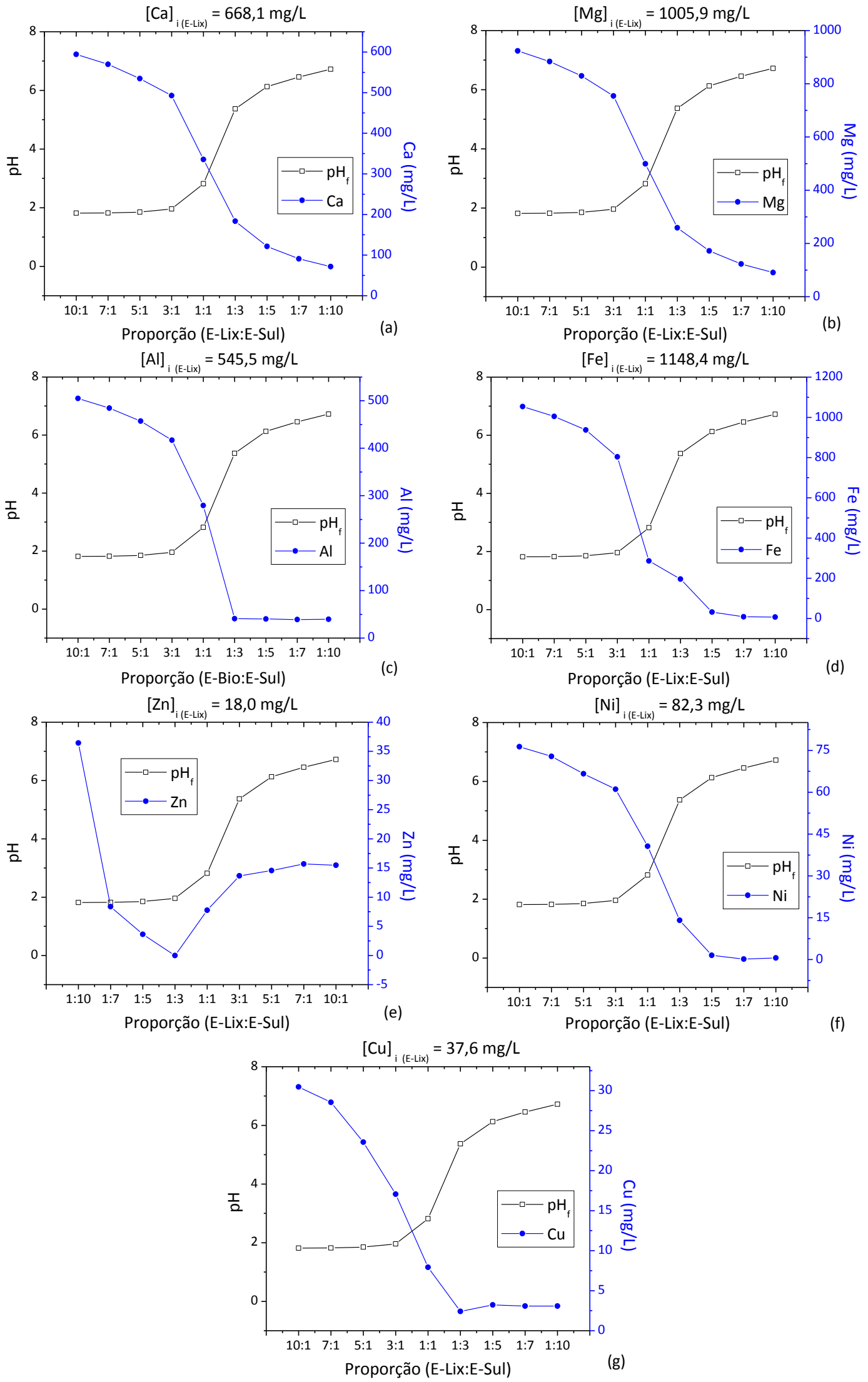

Figura 3. Evolução da concentração dos metais e do pH em função da razão E-Lix:E-Sul. 


\subsection{Ensaios com adição de cal}

Nesta segunda parte dos ensaios, foi feita a neutralização com adição de cal dos efluentes ácidos do laboratório de pesquisa e dos ensaios de lixiviação que foram previamente tratados com o efluente sulfetogênico. Para isso, foram utilizadas as fases líquidas resultantes dos ensaios realizados nas proporções de E-Lab:E-Sul igual a 1:10 e E-Lix:E-Sul igual a (1:1). O teor de cal utilizado para atingir um valor de $\mathrm{pH} 8$ no efluente que foi previamente tratado na proporção 1:10 (E-Lab:E-Sul) foi de 4,8 g/L, enquanto que nos ensaios controle (efluente in natura) foi necessário um teor de cal de $80 \mathrm{~g} / \mathrm{L}$ para alcançar o mesmo valor de pH. Já na proporção de 1:1 (E-Lix:E-Sul), foi utilizado 7,5 gCal/L para chegar ao $\mathrm{pH} 8$, sendo que, nos respectivos ensaios controle, esse teor foi de $40 \mathrm{~g} / \mathrm{L}$ para chegar ao mesmo valor de $\mathrm{pH}$.

Esses resultados demonstram que a utilização desse método foi eficiente na precipitação dos metais remanescentes da primeira etapa da metodologia adotada. E ainda, pode-se destacar a grande diminuição da quantidade de cal gasto para neutralizar o efluente quando comparado com os ensaios controles. Embora o presente trabalho tenha sido empregado em escala de bancada, os resultados obtidos apresentam a viabilidade técnica da metodologia proposta. Logo, essa deve ser testada em outras escalas a fim de se determinar sua eficiência em aplicações industriais.

\section{CONCLUSÕES}

Como uma importante forma de contaminação humana se dá pela ingestão de água contendo teores de metais pesados acima dos teores recomendados, é fundamental a adoção de técnicas eficientes para o tratamento de efluentes com esse perfil. Nessa perspectiva, observouse que a partir do uso do efluente sulfetogênico e posterior tratamento com cal foi possível ajustar os teores metálicos e o pH final aos limites regulamentados pela legislação ambiental brasileira vigente. No caso do efluente originado no laboratório de pesquisa, o qual era mais ácido e apresentava um teor de metais inferior ao efluente produzido em ensaios de lixiviação, os principais resultados observados quando se utilizou a proporção E-Lab:E-Sul igual a 1:10 e realizou os ajustes finais da concentração dos metais e da acidez utilizando um teor de cal igual a 4,8 g/L. Já no caso do efluente de ensaios de lixiviação, os melhores resultados foram obtidos utilizando a proporção de E-Lix:E-Lab igual a 1:3 e realizando os ajustes dos metais e do pH utilizando um teor de cal igual a $7,5 \mathrm{~g} / \mathrm{L}$.

Dessa forma, como no presente trabalho os efluentes estudados foram enquadrados aos padrões de lançamento determinados pelas normas do CONAMA 357/2005 e 430/2011, pode-se afirmar que a metodologia proposta e testada com os efluentes E-Lab e E-Lix contribui para a redução dos impactos ambientais e dos riscos à saúde humana associados ao contato com efluentes de mesmo perfil (ácidos e ricos em metais).

\section{AGRADECIMENTOS}

Os autores agradecem as agências FINEP, FAPEMIG, CNPq e CAPES e à UFOP pelo auxílio fornecido para o suporte deste trabalho. Em especial ao CNPq e CAPES pelas bolsas concedidas. 


\section{REFERÊNCIAS BIBLIOGRÁFICAS}

1. CIMINELLI, V.S.T. Hidrometalurgia - Tendências tecnológicas Brasil 2015: Geociências e Tecnologia Mineral. Rio de Janeiro, CETEM/MCT, Parte II, Cap 4, p 157-174. 2007.

2. BORMA, L. S. e P. S. M. SOARES. Drenagem Ácida e Gestão de Resíduos Sólidos de Mineração. In: Cetem/Mct (Ed.). Extração de ouro: princípios, tecnologia e meio ambiente, 2002. Drenagem Ácida e Gestão de Resíduos Sólidos de Mineração, p.243-266. 2002.

3. INAP - International Network for Acid Prevention: Treatment of sulphate in mine effluents Lorax Environmental. Out. 2003. 129 p.

4. WHO. Guidelines for drinking-water quality. Genebra. 1: 564 p. 2011.

5. CONAMA. RESOLUÇÃO $\mathrm{N}^{\circ}$ 357, DE 17 DE MARÇO 2005. M. D. M. Ambiente: <http://www.mma.gov.br/port/conama/res/res05/res35705.pdf> 2005.

6. CONAMA. RESOLUÇÃO $\mathrm{N}^{\circ}$ 430, DE 13 DE MAIO DE 2011. M. D. M. Ambiente: <http://www.mma.gov.br/port/conama/> 2011.

7. KAKSONEN, A. H. e J. A. PUHAKKA. Sulfate Reduction Based Bioprocesses for the Treatment of Acid Mine Drainage and the Recovery of Metals. Engineering in Life Sciences, v.7, n.6, p.541564. 2007.

8. HUISMAN, J. L., G. SCHOUTEN. Biologically produced sulphide for purification of process streams, effluent treatment and recovery of metals in the metal and mining industry. Hydrometallurgy, v.83, n.1-4, p.106-113. 2006.

9. KLAASSEN, C. D. e J. B. WATKINS. Fundamentos em toxicologia de Cassaret e Doull, v. único. 2010. 